\title{
PENGARUH MOTIVASI BELAJAR, PERILAKU BELAJAR DAN MODEL PEMBELAJARAN KONSTRUKTIVISME TERHADAP PRESTASI BELAJAR MAHASISWA KELAS REGULER FAKULTAS EKONOMI DAN BISNIS UIN SYARIF HIDAYATULLAH JAKARTA
}

\author{
Soliyah Wulandari \\ UIN Syarif Hidayatullah Jakarta \\ Email:soliyah.wulandari@uinjkt.ac.id
}

\begin{abstract}
ABSTRAK
Penelitian ini bertujuan untuk menjelaskan pengarub motivasi belajar, perilaku belajar, dan model pembelajaran konstruktivisme terbadap prestasi belajar. Perilaku belajar terdiri dari kebiasaan mengikuti pelajaran, kebiasaan membaca buku teks, kunjungan ke perpustakaan, dan kebiasaan mengikuti ujian. Sampel yang digunakan di dalam penelitian ini dihasilkan melalui teknik pengambilan sampel bertujuan dari mahasiwa-mahasiwa jurusan akuntansi, manajemen, dan ilmu ekonomi studi pembangunan kelas reguler Fakultas Ekonomi dan Bisnis UIN Syarif Hidayatullah Jakarta. Sampel akhir dari penelitian ini adalah 202 mahasiswa. Data dianalisis dengan menggunakan regresi berganda. Hasil dari penelitian ini memberikan dukungan secara empiris bahwa perilaku belajar dalam hal kebiasaaan mengikuti pelajaran dan kunjungan ke perpustakaan berpengarub terbadap prestasi belajar mahasiswa. Namun, hasil penelitian ini tidak memberikan dukungan secara empiris bahwa motivasi belajar, perilaku belajar dalam hal kebiasaan membaca buku teks dan kebiasaan mengikuti ujian, serta model pembelajaran konstruktivisme berpengaruh terbadap prestasi belajar mahasiswa.
\end{abstract}

Kata kunci: motivasi belajar, perilaku belajar, model pembelajaran konstruktivisme, prestasi belajar.

\section{PENDAHULUAN}

Pada hakikatnya pendidikan merupakan suatu usaha yang dilakukan oleh manusia untuk meninkatkan hidup ke arah yang lebih sempurna. Pendidikan juga merupakan suatu kekuatan dinamis yang sangat berpengaruh terhadap perkembangan fisik, mental, etika dan seluruh aspek kehidupan manusia.

Kualitas manusia berkaitan erat dengan kualitas pendidikan, yang merupakan rangkaian dari pendidikan tingkat dasar, menengah dan tinggi. Pendidikan tinggi sebagai lembaga yang membekali peserta diik dengan penekanan pada alar dan pemahaman pengetahuan berdasarkan keterkaitan antara teori dengan pengaplikasiannya dalam dunia praktik, berperan penting dlaam menumbuhkembangkan kemandirian peserta didik dalam proses pembelajaran yang diikutinya.

Menurut Suwardjono (1992) belajar di perguruan tinggi merupakan pilihan startegik untuk mencapai tujuan individual bagi mereka yang menyatakan dirinya untuk belajar melalui jalur formal tersebut. Kesenjangan perspsi dan pemahaman penyelenggaram pendidikan, dosen dan mahasiswa di perguruan tingi dapat menyebabkan proses belajar-mengajar bersifat 
disfungsional.

Belajar merupakan hak setiap orang. Akan tetapi, kegiatan belajar di suatu perguruan tinggi merupakan suatu privelege karena hanya orang yang memenuhi syarat saja dapat dan berhak belajar di lembaga pendidikan tersebut. Apabila mereka yang telah memiliki privelege akhirnya berbuat atau bertindak seperti mereka tidak belajar melalui lembaga formal, maka mereka yang berstatus sebagai mahasiswa sebenarnya tidak berbeda dengan mereka yang tidak melalui lembaga formal, kecuali bahwa mereka yang belajar di perguruan tinggi mempunyai kartu mahasiswa dan dianggap statusnya lebih tinggi.

Prestasi belajar pada hakekatnya adalah pencerminan dari usaha belajar, semakin baik usaha untuk belajar semakin baik pula prestasi yang dicapai. Prestasi akademik yang dicapai seorang mahasiswa merupakan hasil dari interaksi antara berbagai faktor yang mempengaruhinya, baik dari dalam (internal) maupun dari luar diri mahasiwa (faktor eksternal). Pengenalan terhadap faktor-faktor yang mempengaruhi prestasi akademik diperlukan unuk memahami bagaimana perubahan dalam determinan tersebut berhubungan dengan perubahan prestasi, sehingga pada akhirnya menjadi rekomendasi bagi pengambilan kebijakan dalam pendidikan akuntansi.

Ada beberapa faktor yang mempengaruhi prestasi belajar. Contoh faktor yang berasal dari dalam diri mahasiswa (internal) adalah motivasi belajar dan perilaku belajar, sedangkan contoh faktor yang berasal dari luar diri mahasiswa (eksternal) adalah model pembelajaran. Motivasi belajar bisa timbul dalam maupun dari luar. Motivasi yang muncul dari dalam diri seorang mahasiswa akan lebih stabil dan mantap bila dibandingkan dengan motivasi yang muncul karena pengaruh dari luar. Mahasiswa yang memiliki motivasi yang tinggi dalam belajar cenderung lebih aktif dalam usaha meningkatkan prestasinya.

Menurut Hamalik (1983), salah satu faktor yang bersumber dari dalam diri sendiri adalah kebiasaan belajar, atau tepatnya perilaku belajar. Rampengan (1997) berpendapat bahwa perilaku belajar merupakan kebiasaan belajar yang dilakukan oleh individu secara berulang-ulang sehingga menjadi otomatis atau berlangsung secara spontan. Perilaku belajar tidak lagi dirasakan sebagai beban, melainkan sebuah kebutuhan. Hal ini tercipta karena secara terus menerus dilakukan dengan bimbingan dan pengawasan serta keteladanan dalam semua aspek dan kreativitas pendidikan.

Salah satu strategi yang dapat ditempuh guna memperbaiki proses pembelajaran Akuntansi adalah dengan melakukan redesain pembelajaran dari model pembelajaran konvensional menuju desain sesuai dengan pandangan konstruktivistik. Menurut Bettencourt (1989) dalam Suparno (1997), dalam model pembelajaran konstruktivis, pengetahuan tidak diterima secara pasif, tetapi dibangun secara aktif oleh learner. Ide-ide dan pikiran-pikiran tidak dapat dipaket ke dalam kata-kata, lalu di transfer kepada orang lain. Pengajar tidak dapat 
menaruh ide yang dimilikinya ke dalam kepala pembelajar. Learner itu sendirilah yang membangun makna terhadap masukan sensori yang diterima dalam lingkungannya sesuai dengan prior knowledge yang dimiliki leaners. Beberapa penelitian telah dilakukan terkait dengan implementasi model konstruktivis dalam pembelajaran. Sadia (1996) melakukan studi dengan menerapkan model belajar konstruktivis dalam pembelajaran konsep Energi, Usaha dan Suhu. Temuan penelitian ini menunjukkan bahwa model belajar konstruktivis memiliki keunggulan komparatif terhadap model belajar konvensional.

Berdasarkan uraian di atas, peneliti tertarik untuk melakukan penelitian mengenai faktorfaktor yang berpengaruh terhadap prestasi mahasiswa. Faktor-faktor yang dimaksud adalah motivasi belajar, perilaku pelajar, dan model pembelajaran konstruktivisme. Peneliti ingin melakukan penelitian tersebut di lingkungan Fakultas Ekonomi dan Bisnis UIN Syarif Hidayatullah Jakarta. Oleh karena itu, judul dari penelitian ini adalah "Pengaruh Motivasi Belajar, Perilaku Belajar, dan Model Pembelajaran Konstruktivisme terhadap Prestasi Belajar Mahasiswa Kelas Reguler Fakultas Ekonomi dan Bisnis UIN Syarif Hidayatullah Jakarta.

\section{METODOLOGI PENELITIAN}

\section{Populasi dan Sampel}

Populasi dalam penelitian ini adalah mahasiswa Fakultas Ekonomi dan Bisnis Kelas Reguler UIN Syarif Hidayatullah Jakarta. Sampel dan responden dalam penelitian ini adalah mahasiswa Jurusan Akuntansi, Manajemen, Ilmu Ekonomi Studi Pembangunan (IESP) angkatan tahun akademik 2008/2009, 2009/2010, 2010/2011 dan 2011/2012.

\section{Teknik Pemilihan Sampel}

Untuk mencapai tujuan penelitian, teknik penentuan sampel pada penelitian ini adalah menggunakan metode purposive random sampling sebagai penentuan sampelnya. purposive random sampling jenis judgement sampling merupakan teknik pengambilan sampel dengan pertimbangan atau kriteria tertentu (Sekaran dan Bougie, 2010). Dimana mahasiswa yang akan menjadi responden dalam penelitian ini paling tidak sudah melewati 1 (satu) tahun perkuliahan, sehingga mahasiswa yang menjadi responden dalam penelitian ini adalah mahasiswa Jurusan Akuntansi, Manajemen, Ilmu Ekonomi Studi Pembangunan (IESP) angkatan tahun akademik 2008/2009, 2009/2010, 2010/2011 dan 2011/2012. Sedangkan angkatan 2012/2013 tidak diikutsertakan, karena baru saja memasukki bangku perkuliahan.Jenis data dalam penelitian ini adalah data primer. Data primer berupa pengumpulan data melalui penyebaran kuesioner. 


\section{Definisi Operasional Variabel dan Pengukurannya}

\section{Variabel Independen}

Variabel-variabel independen yang terdapat di dalam penelitian ini diukur dengan menggunakan instrumen, yaitu melalui kuesioner yang dirancang oleh peneliti berdasarkan beberapa referensi, kemudian disesuaikan dengan kondisi dan keadaan di lingkungan FEB UIN Syarif Hidayatullah Jakarta.

a. Motivasi Belajar

Motivasi belajar diukur dengan menggunakan skala interval 5 poin, dengan nilai terendah adalah 1 (satu) dan nilai tertinggi adalah 5 (lima). Jumlah pertanyaannya adalah 17 butir pertanyaan yang terkait motivasi mahasiswa dalam belajar.

b. Perilaku Belajar

Belajar belajar diukur dengan menggunakan skala interval 5 poin. Jumlah pertanyaannya adalah 4 butir pertanyaan yang terkait dengan seberapa sering mahasiswa masuk ke kelas untuk mengikuti pelajaran, membaca buku teks, mengunjungi perpustakaan, dan kebiasaan mengikuti ujian. Nilai terendah adalah 1 (satu) yang artinya adalah "Sangat Jarang" dan nilai tertinggi adalah 5 (lima) yang artinya adalah "Sangat Sering".

c. Model Pembelajaran Konstruktivisme

Model pembelajaran konstruktivisme diukur dengan menggunakan skala interval 5 poin, dengan nilai terendah adalah 1 (satu) dan nilai tertinggi adalah 5 (lima). Jumlah pertanyaannya adalah 4 butir pertanyaan yang terkait model pembelajaran konstruktivisme.

\section{Variabel Dependen}

Variabel dependen dalam penelitian ini adalah prestasi belajar. Prestasi belajar diukur melalui Indeks Prestasi Kumulatif (IPK) setiap mahasiswa yang diskalakan dengan menggunakan skala interval 5 poin, dengan nilai terendah adalah 1 (satu) dan nilai tertinggi adalah 5 (lima) yang dijelaskan lebih rinci di dalam tabel di bawah ini:

Tabel 1

Interval Pengukuran Prestasi Belajar

\begin{tabular}{|c|c|}
\hline Poin & IPK Mahasiswa \\
\hline 1 & 0,00 s.d. 1,99 \\
\hline 2 & 2,00 s.d. 2,74 \\
\hline 3 & 2,75 s.d. 2,99 \\
\hline 4 & 3,00 s.d. 3,49 \\
\hline 5 & 3,50 s.d. 4,00 \\
\hline
\end{tabular}

Sumber : data diolah 


\section{Metode Analisis Data}

Sebelum melakukan uji analisis data, jawaban dari butir-butir pertanyaan kuesioner yang digunakan di dalam penelitian ini terlebih dahulu dilakukan uji validitas dan reliabilitas data. Uji validitas data dilakukan dengan menggunakan perason's correlation, sedangkan uji reliabiliras data dilakukan dengan menggunakan cronbach alpha. Setelah melakukan uji validitas dan reliabilitas data, peneliti melakukan uji asumsi klasik.

Analisis data yang digunakan di dalam penelitian ini adalah regresi berganda (multiple regressions). Di bawah ini merupakan persamaan regresi yang digunakan dalam penelitian ini

$$
\mathrm{Y}=\beta_{0}+\beta_{1} \mathrm{X}_{1}+\beta_{2} \mathrm{X}_{2}+\beta_{3} \mathrm{X}_{3}+\beta_{4} \mathrm{X}_{4}+\beta_{5} \mathrm{X}_{5}+\beta_{6} \mathrm{X}_{6}+e
$$

Keterangan:

$$
\begin{aligned}
& \mathrm{Y}=\text { Prestasi Belajar } \\
& \mathrm{X}_{1}=\text { Motivasi Belajar } \\
& \mathrm{X}_{2}=\text { Kebiasaan Mengikuti Pelajaran } \\
& \mathrm{X}_{3}=\text { Kebiasaan Membaca Buku Teks } \\
& \mathrm{X}_{4}=\text { Kunjungan ke Perpustakaan } \\
& \mathrm{X}_{5}=\text { Kebiasaan Mengikuti Ujian } \\
& \mathrm{X}_{6}=\text { Metode Pembelajaran Konstruktivisme } \\
& e
\end{aligned}
$$

Hipotesis diterima atau didukung jika nilai p-value (signifikansi) sama dengan atau di bawah $0,05(\leq 0,05)$.

\section{PEMBAHASAN}

\section{Deskripsi Umum Sampel}

Kuesioner penelitian yang disebarkan kepada responden terdiri dari 25 butir pertanyaan. Dari 25 butir pertanyaan tersebut, 17 butir pertanyaan terkait dengan motivasi belajar, 4 butir pertanyaan terkait dengan perilaku belajar, dan 4 butir pertanyaan terkait dengan metode pembelajaran konstruktivisme. Kuesioner-kuesioner yang didistribusikan kepada para responden, dapat dilihat pada Tabel 2 di bawah ini.

\section{Tabel 2}

Data Sampel Penelitian

\begin{tabular}{|c|l|r|}
\hline No. & \multicolumn{1}{|c|}{ Keterangan } & \multicolumn{1}{|c|}{ Jumlah } \\
\hline 1. & Kuesioner yang didistribusikan. & 52 \\
\hline 2. & $\begin{array}{l}\text { Kuesioner yang tidak kembali/tidak dapat digunakan } \\
\text { dalam penelitian. }\end{array}$ & 202 \\
\hline 3. & Kuesioner yang dapat digunakan dalam penelitian. & \\
\hline
\end{tabular}

Sumber : Data diolah

Informasi mengenai demografi responden dibagi menjadi 3 (tiga) bagian, yaitu: jenis 
kelamin, angkatan, dan jurusan. Tabel 3 di bawah ini menjelaskan mengenai ketiga informasi terkait demografi responden.

Tabel 3

Demografi Responden

\begin{tabular}{|c|l|r|r|}
\hline No & \multicolumn{1}{|c|}{ Keterangan } & Jumlah & \multicolumn{1}{c|}{$\%$} \\
\hline 1. & Jenis Kelamin & 74 & 37 \\
& Laki-laki & 128 & 63 \\
\hline \multirow{2}{*}{ Perempuan } & Angkatan & & \\
& 2011 & 15 & 7 \\
& 2010 & 114 & 56 \\
& 2009 & 56 & 28 \\
& 2008 & 17 & 8 \\
\hline 3. & Jurusan & 100 & 50 \\
& Akuntansi & 62 & 30 \\
& Manajemen & 40 & 20 \\
\hline
\end{tabular}

Sumber : Data diolah

Berdasarkan Tabel 3 terlihat bahwa dari jumlah kuesioner yang kembali sebanyak 202 buah, 74 buah kuesioner (37\%) diisi oleh laki-laki, sedangkan sebanyak 128 buah kuesioner $(63 \%)$ diisi oleh perempuan. Selain itu, berdasarkan informasi angkatan, yang paling banyak mengisi kuesioner adalah angkatan 2010 yaitu sebanyak 114 buah (56\%), selanjutnya angkatan 2009 sebanyak 56 buah (28\%), angkatan 2008 sebanyak 17 buah (8\%), dan terakhir angkatan 2011 sebanyak 15 buah (15\%). Informasi yang ketiga yaitu jurusan. Di mana dari 202 buah kuesioner yang dapat digunakan sebanyak 100 buah (50\%) diisi oleh mahasiswa reguler jurusan akuntansi, 62 buah (30\%) diisi oleh mahasiswa reguler jurusan manajemen, dan sisanya sebanyak 40 buah $(20 \%)$ diisi oleh mahasiswa reguler jurusan IESP.

\section{Statistik Deskriptif}

Tabel 4 di bawah ini menyajikan statistik deskriptif variabel-variabel utama dalam sampel jawaban kuesioner yang diberikan mahasiswa reguler FEB UIN Syarif Hidayatullah Jakarta. Berdasarkan tabel tersebut, nilai minimum dari motivasi belajar sebesar 43 dan nilai maksimum sebesar 71. Nilai minimum dari kebiasaan mengikuti pelajaran sebesar 1 dan nilai maksimum sebesar 5. Nilai minimum dari kebiasaan membaca buku teks sebesar 1 dan nilai maksimum sebesar 5. Nilai minimum dari kunjungan ke perpustakaan sebesar 1 dan nilai maksimum sebesar 5. Nilai minimum dari kebiasaan mengikuti ujian sebesar 1 dan nilai maksimum sebesar 5. Nilai minimum dari metode pembelajaran konstruktivisme sebesar 3 dan nilai maksimum sebesar 17. Terakhir, nilai minimum dari prestasi belajar sebesar 2,20 dan nilai maksimum sebesar 3,85 . 
Tabel 4

Statistik Deskriptif Variabel Utama

\begin{tabular}{|l|r|r|r|r|r|}
\hline \multicolumn{1}{|c|}{ Variabel } & \multicolumn{1}{c|}{ N } & Minimum & Maximum & \multicolumn{1}{c|}{ Mean } & Std. Deviation \\
\hline Motivasi Belajar & 202 & 43.00 & 71.00 & 57.4703 & 4.81205 \\
\hline Kebiasaan Mengikuti Pelajaran & 202 & 1.00 & 5.00 & 4.5446 & .62334 \\
\hline Kebiasaan Membaca Buku Teks & 202 & 1.00 & 5.00 & 3.1931 & .75135 \\
\hline Kunjungan ke Perpustakaan & 202 & 1.00 & 5.00 & 3.0248 & .86639 \\
\hline Kebiasaan Mengikuti Ujian & 202 & 1.00 & 5.00 & 3.4554 & .84081 \\
\hline $\begin{array}{l}\text { Metode Pembelajaran } \\
\text { Konstruktivisme }\end{array}$ & 202 & 3.00 & 17.00 & 11.1881 & 1.88058 \\
\hline Prestasi Belajar & 202 & 2.20 & 3.85 & 3.2223 & .34156 \\
\hline
\end{tabular}

Sumber : Data diolah

\section{Pengujian Hipotesis dan Pembahasan}

\section{Hasil Uji Validitas dan Reliabilitas}

Suatu kuesioner dikatakan valid jika butir pertanyaan pada suatu kuesioner mampu untuk mengungkapkan sesuatu yang akan diukur oleh kuesioner tersebut. Oleh karena itu kuesioner yang diolah akan diuji validitas dan reliabilitasnya. Pengujian validitas yang digunakan pada penelitian ini menggunakan pearson's correlation. Butir pertanyaan dikatakan valid jika nilai signifikansi lebih kecil dari 0,05 dan 0,01 (Ghozali, 2005).

Tabel 5 berikut ini menjelaskan hasil pengujian validitas untuk setiap butir pertanyaan yang digunakan dalam penelitian ini. Berdasarkan tabel 4.4 terlihat bahwa seluruh butir pertanyaan mempunyai nilai $\mathrm{p}$-value $<0,05$, hal ini menunjukkan bahwa seluruh butir pertanyaan yang digunakan dalam penelitian ini valid, artinya setiap butir pertanyaan tersebut mampu untuk mengungkapkan sesuatu yang akan diukur oleh kuesioner tersebut.

Tabel 5

Hasil Uji Validitas

\begin{tabular}{|c|r|r|c|}
\hline Butir Pertanyaan & $\begin{array}{c}\text { Pearson's } \\
\text { Correlation }\end{array}$ & P-Value & Keterangan \\
\hline Pertanyaan ke-1 & 0,349 & 0,000 & Valid \\
\hline Pertanyaan ke-2 & 0,553 & 0,000 & Valid \\
\hline Pertanyaan ke-3 & 0,520 & 0,000 & Valid \\
\hline Pertanyaan ke-4 & 0,461 & 0,000 & Valid \\
\hline Pertanyaan ke-5 & 0,332 & 0,000 & Valid \\
\hline Pertanyaan ke-6 & 0,238 & 0,001 & Valid \\
\hline Pertanyaan ke-7 & 0,443 & 0,000 & Valid \\
\hline Pertanyaan ke-8 & 0,152 & 0,030 & Valid \\
\hline Pertanyaan ke-9 & 0,405 & 0,000 & Valid \\
\hline Pertanyaan ke-10 & 0,375 & 0,000 & Valid \\
\hline Pertanyaan ke-11 & 0,174 & 0,013 & Valid \\
\hline Pertanyaan ke-12 & 0,260 & 0,000 & Valid \\
\hline Pertanyaan ke-13 & 0,235 & 0,001 & Valid \\
\hline
\end{tabular}




\begin{tabular}{|c|r|r|c|}
\hline Butir Pertanyaan & $\begin{array}{c}\text { Pearson's } \\
\text { Correlation }\end{array}$ & P-Value & Keterangan \\
\hline Pertanyaan ke-14 & 0,209 & 0,003 & Valid \\
\hline Pertanyaan ke-15 & 0,451 & 0,000 & Valid \\
\hline Pertanyaan ke-16 & 0,479 & 0,000 & Valid \\
\hline Pertanyaan ke-17 & 0,408 & 0,000 & Valid \\
\hline Pertanyaan ke-18 & 0,307 & 0,000 & Valid \\
\hline Pertanyaan ke-19 & 0,613 & 0,000 & Valid \\
\hline Pertanyaan ke-20 & 0,436 & 0,000 & Valid \\
\hline Pertanyaan ke-21 & 0,392 & 0,000 & Valid \\
\hline Pertanyaan ke-22 & 0,572 & 0,000 & Valid \\
\hline Pertanyaan ke-23 & 0,290 & 0,000 & Valid \\
\hline Pertanyaan ke-24 & 0,366 & 0,000 & Valid \\
\hline Pertanyaan ke-25 & 0,261 & 0,000 & Valid \\
\hline
\end{tabular}

Sumber : Data diolah

Setelah menentukan validitas instrumen penelitian, tahap selanjutnya adalah mengukur relibilitas data instrumen penelitian, pengujian reabilitas dalam penelitian ini adalah Cronbach Alpha karena menggunakan jenis data likert/essay. Teknik ini dapat menafsirkan korelasi antara skala diukur dengan semua variabel yang ada.

Penelitian ini menggunakan bantuan program SPSS dalam menghitung Cronbach Alpha, untuk menginterpretasikan nilai alpha yang diperoleh. Jika Cronbach Alpha $>0,6$ maka reliabilitas pertanyaan untuk mengukur variabel-variabel tersebut tinggi/bisa diterima (Ghozali, 2005). Tabel 6 berikut ini menjelaskan hasil pengujian reliabilitas instrumen yang digunakan dalam penelitian ini.

Tabel 6

Hasil Uji Reliabilitas

\begin{tabular}{|c|c|c|}
\hline $\begin{array}{c}\text { Cronbach's } \\
\text { Alpha }\end{array}$ & N & Keterangan \\
\hline 0,721 & 25 & Reliabel \\
\hline
\end{tabular}

Sumber : Data diolah

Berdasarkan tabel 6 terlihat bahwa nilai Cronbach's Alpha 0,723 >0,6, hal ini menunjukkan bahwa instrumen yang digunakan dalam penelitian ini reliabel, artinya reliabilitas pertanyaan untuk mengukur variabel-variabel tersebut tinggi/bisa diterima.

\section{$\underline{\text { Hasil Uji Hipotesis }}$}

Hasil uji asumsi klasik yang telah dilakukan menunjukkan bahwa seluruh asumsi klasik telah terpenuhi. Hipotesis 1 ditujukan untuk menguji pengaruh motivasi belajar terhadap prestasi belajar mahasiswa reguler FEB UIN Syarif Hidayatullah Jakarta. Hipotesis 2 ditujukan untuk menguji pengaruh perilaku belajar terhadap prestasi belajar mahasiswa reguler FEB UIN Syarif Hidayatullah Jakarta, dimana perilaku belajar ini diukur dengan kebiasaan mengikuti pelajaran $\left(\mathrm{H}_{2 \mathrm{a}}\right)$, kebiasaan membaca buku teks $\left(\mathrm{H}_{2 \mathrm{~b}}\right)$, kunjungan ke perpustakaan $\left(\mathrm{H}_{2 \mathrm{c}}\right)$, dan kebiasaan mengikuti ujian $\left(\mathrm{H}_{2 \mathrm{~d}}\right)$. Terakhir, hipotesis 3 ditujukan untuk menguji pengaruh 
metode pembelajaran konstruktivisme terhadap prestasi belajar mahasiswa reguler FEB UIN Syarif Hidayatullah Jakarta.

Hasil pengujian regresi berganda disajikan di Tabel 7 di bawah ini:

Tabel 7

Hasil Regresi

\begin{tabular}{|l|r|r|r|r|c|}
\hline \multicolumn{1}{|c|}{ Variabel } & Koefisien & Std. Error & t-tabel & $p$-value & Signifikansi \\
\hline Konstanta & 2,397 & 0,310 & 7,743 & 0,000 & \\
\hline Motivasi Belajar & 0,000 & 0,005 & $-0,32$ & 0,974 & Tidak Signifikan \\
\hline $\begin{array}{l}\text { Kebiasaan Mengikuti } \\
\text { Pelajaran }\end{array}$ & 0,103 & 0,38 & 2,693 & 0,008 & Signifikan \\
\hline $\begin{array}{l}\text { Kebiasaan Membaca } \\
\text { Buku Teks }\end{array}$ & 0,030 & 0,038 & 0,801 & 0,424 & Tidak Signifikan \\
\hline $\begin{array}{l}\text { Kunjungan ke } \\
\text { Perpustakaan }\end{array}$ & 0,075 & 0,030 & 2,514 & 0,013 & Signifikan \\
\hline $\begin{array}{l}\text { Kebiasaan Mengikuti } \\
\text { Ujian }\end{array}$ & 0,007 & 0,029 & 0.253 & 0,801 & Tidak Signifikan \\
\hline $\begin{array}{l}\text { Metode Pembelajaran } \\
\text { Konstruktivisme }\end{array}$ & 0,002 & 0,014 & 0,138 & 0,891 & Tidak Signifikan \\
\hline \multicolumn{7}{|c|}{ Nilai F 3,747 dengan Signifikansi 0,001} & \\
\hline
\end{tabular}

Dependent variable: Prestasi Belajar

Hasil analisis yang disajikan dalam tabel 7 menunjukkan bahwa kebiasaan mengikuti pelajaran dan kunjungan ke perpustakaan masing-masing mempunyai nilai p-value sebesar 0,008 dan 0,013 . $(<0,05)$. Hal ini berarti hipotesis 2 a dan hipotesis 2 c didukung, yang berarti bahwa data empiris yang ada sesuai dengan prediksi yaitu kebiasaan mengikuti pelajaran dan kunjungan ke perpustakaan berpengaruh terhadap prestasi belajar mahasiswa regular FEB UIN Syarif Hidayatullah Jakarta.

Sedangkan motivasi belajar, kebiasaan membaca buku teks, kebiasaan mengikuti ujian dan metode pembelajaran konstruktivisme masing-masing mempunyai nilai p-value sebesar 0,974; 0,424; 0,801; dan 0,891 (>0,05). Hal ini berarti hipotesis 1 , hipotesis $2 \mathrm{~b}$, hipotesis $2 \mathrm{~d}$, dan hipotesis 3 tidak didukung, yang berarti bahwa data empiris yang ada tidak sesuai dengan prediksi yaitu motivasi belajar, kebiasaan membaca buku teks, kebiasaan mengikuti ujian dan metode pembelajaran konstruktivisme tidak berpengaruh terhadap prestasi belajar mahasiswa regular FEB UIN Syarif Hidayatullah Jakarta.

\section{KESIMPULAN}

Tujuan penelitian ini adalah ingin membuktikan secara empiris pengaruh faktor-faktor terhadap prestasi belajar mahasiswa reguler FEB UIN Syarif Hidayatullah Jakarta. Faktor-faktor yang dimaksud adalah motivasi belajar, perilaku belajar yang terdiri atas kebiasaan mengikuti 
pelajaran, kebiasaan membaca buku teks, kunjungan ke perpustakaan, dan kebiasaan mengikuti ujian, dan faktor yang terakhir yaitu metode pembelajaran konstruktivisme.

Setelah diuji dengan menggunakan regresi berganda, maka diperoleh kesimpulan sebagai berikut:

a. Kebiasaan mengikuti pelajaran dan kunjungan ke perpustakaan berpengaruh terhadap prestasi belajar mahasiswa reguler FEB UIN Syarif Hidayatullah Jakarta.

b. Motivasi belajar, kebiasaan membaca buku teks, kebiasaan mengikuti ujian dan metode pembelajaran konstruktivisme tidak berpengaruh terhadap prestasi belajar mahasiswa reguler FEB UIN Syarif Hidayatullah Jakarta.

Penelitian ini dapat menjadi bahan pertimbangan bagi perguruan tinggi khususnya fakultas ekonomi untuk lebih memperhatikan lagi usaha-usaha yang seharusnya dilakukan bagi sebuah institusi pendidikan untuk meningkatkan prestasi belajar mahasiwanya. Kebiasaan mahasiswa mengikuti pelajaran menjadi begitu sangat penting dalam suatu proses belajar mengajar. Hadirnya seorang mahasiswa di dalam kelas akan menambah pengetahuan dan pelajaran bagi mahasiswa yang bersangkutan. Ditambah lagi proses pembelajaran yang berbeda antara Perguruan Tinggi dengan sekolah, di Perguruan Tinggi seorang mahasiswa dianggap sudah dewasa dan mandiri, selain itu banyaknya sks yang harus diselesaikan dalam jangka waktu tertentu, sehingga dosen biasanya hanya menjelaskan 30\% dari materi yang seharusnya diterima mahasiswa. Jika 1x (satu kali) saja mahasiswa tersebut tidak mengikuti perkuliahan, akan ada banyak materi yang tertinggal, khususnya dalam matakuliah yang bersangkutan. Oleh karena itu, sebaiknya perguruan tinggi lebih memperhatikan lagi bagaimana usaha untuk membuat mahasiswa rajin masuk ke kelas untuk mengikuti perkuliahan.

Menerima materi atau pelajaran di kelas tidak cukup untuk memperoleh ilmu dan kemampuan yang mempuni. Mahasiswa juga diharapkan rajin untuk melakukan kunjungan ke perpustakaan. Aka nada banyak hal yang diperoleh ketika mahasiswa terebut ke perpustakaan. Mahasiwa tidak hanya mendapatkan ilmu dari buku teks wajib, tetapi juga bisa menambahkannya dari buku teks lain yang disediakan di perpustakaan. Dengan begitu, ilmu yang akan diperoleh seotang mahasiswa akan lebih komprehensif dari berbagai sudut pandang. Oleh karena itu, institusi pendidikan khususnya perguruan tinggi lebih membuat usaha agar mahasiswa terstimulus untuk mengunjungi perpustakaan yang merupakan tempat segudang ilmu.

\section{REFERENSI}

Astuti, Endang Sri dan Resminingsih. 2010. Bahan Dasar untuk Pelayanan Konseling Pada Satuan Pendidikan Menengah Jilid I. Jakarta: PT. Grasindo.

Daroca, F.P. dan M.M. Nourayi. 1994. Some Performance and Attitude Effects on Students in 
Managerial Accounting: Lecture vs Self Study Courses. Issues in Accounting Education (Fall): 319-329.

Faizin. 2010. Pengaruh Motivasi Belajar dan Disiplin Belajat terhadap Prestasi Belajar Siswa Kelas XI SMK Patiunus Karangawen Jurusan Teknik Otomotif Tabun Pelajaran 2010/2011. E-Journal IKIP Veteran.

Ghozali, Imam. 2005. Aplikasi Analisis Multivariate Dengan Program SPSS. Universitas Diponegoro. Semarang.

Handoko, T. Hani. 1995. Manajemen. Edisi Kedua. Yogyakarta: BPFE Yogyakarta Hasibuan.

Hanifah, Abdullah, Syukriy. 2001. Pengarub Perilaku Belajar terbadap Prestasi Akademik Mahasiswa Akuntansi. Media Riset Akuntansi, Auditing dan Informasi, Vol. 1 No. 3.

Hamalik, O. 1983. Metode Belajar dan Kesulitan-Kesulitan Belajar. Bandung: Tarsito.

Kairullah. 1996. Korelasi antara Minat Baca terhadap Prestasi Belajar Mahasiswa pada Politeknik Universitas Syaiah Kuala. KKI. Tidak Diterbitkan.

Main, M., Amirullah, Yusnani, Mawardi, dan Amiruddin. 1995. Kebiasaan Belajar Mahasiswa FKIP Unsyiah dan Hubungan dengan Prestasi Belajar. KKI. Tidak Diterbitkan.

Manullang. 1982. http://www.motivasi kerja.com/"27 Agustus 2010.

Pudiyanti, Ikha. 2009. Pengaruh Motivasi Belajar, Sikap Belajar, dan Aktualisai Diri terhadap Prestasi Belajar Mahasiswa Pendidikan Ekonomi Akuntansi Universitas Mubammadiyyah Surakarta. Skripsi.

Rampengan, M.J. 1997. Faktor-Faktor Penentu dalam Meningkatkan Prestasi Belajar Mabasiswa. PGSD IKIP Manado. Jurnal MK IKIP Manado, No. 2, Tahun I, September.

Rosniza. 1995. Hubungan Kebiasaan Belajar Siswa dengan Prestasi Belajar pada Siswa Kelas II SMA Negeri Beureuneuen. Skripsi S1. Banda Aceh: Fakultas Keguruan dan Ilmu Pendidikan Universitas Syiah Kuala (Tidak Diterbitkan).

Rusdiana, Ria. 2010. Pengarub Motivasi Belajar terbadap Prestasi Belajar Siswa di MTsN Batu Malang. Skripsi S1. Malang: Universitas Islam Negeri (UIN) Malang.

Sadia, I W. 1996. "Pengembangan Model Belajar Konstruktivis Dalam Pembelajaran IPA di SMP. (Suatu Studi Eksperimental Dalam Pembelajaran Konsep Energi Usaha dan Subu di SMPN 1 Singaraja)". Disertasi (tidak diterbitkan). IKIP Bandung.

Sardiman, A. 2001. Interaksi dan Motivasi Belajar Mengajar. Jakarta: PT. Raja.

Sekaran, Uma, dan Roger Bougie. 2010. Research Methods for Business: A Skill Buiding Approach. John Wiley and Sons Inc.

Suandi, I Ketut. 2009. Evaluasi Keefektifan Model Pembelajaran Konstruktivis dalam Pencapaian Hasil Belajar Pengantar Akuntansi pada Bidang Tata Niaga Politeknik Negeri Bali. Jurnal Pendidikan dan Pengajaran UNDIKSHA Edisi Khusus.

Suparno, P. 1997. Filsafat Konstruktivisme Dalam Pendidikan. Yogyakarta: Kanisius. 
PENGARUH MOTIVASI BELAJAR, PERILAKU BELAJAR...

Suwardjono. 1992. Perilaku Belajar di Perguruan Tinggi Gagasan Pengembangan Profesi dan Pendidikan Akuntansi di Indonesia. Kumpulan Artikel. Yogyakarta: BPFE.

Syukri. 1995. Kebiasaan Belajar Mahasiswa pada Program Studi Pendidikan Dunia Usaha Ekonomi Koperasi Fakultas Keguruan dan Ilmu Pendidikan Universitas Syiah Kuala. Banda Aceh: Fakultas Keguruan dan Ilmu Pendidikan Universitas Syiah Kuala (Tidak Diterbitkan). 